\title{
A Comparative Study of Surface Acid-Base Characteristics of Natural Illites from Different Origins
}

\author{
Wenxin Liu, ${ }^{*} \dagger$ Zhongxi Sun,* Willis Forsling, ${ }^{* 1}$ Qing Du, ${ }^{*} \dagger$ and Hongxiao Tang $\dagger$ \\ *Division of Inorganic Chemistry, Luleå University of Technology, S-97187, Luleå, Sweden; and †SKLEAC, \\ Research Center for Eco-Environmental Sciences, Academia Sinica, Beijing 100085, China \\ Received February 3, 1999; accepted July 23, 1999
}

The acid- base characteristics of naturally occurring illites, collected from different locations, were investigated by potentiometric titrations. The experimental data were interpreted using the constant capacitance surface complexation model. Considerable release of AI and Si from illite samples and subsequent complexation or precipitation of hydroxyl aluminosilicates generated during the acidimetric forward titration and the alkalimetric back titration, respectively, were observed. Therefore, the acidimetric supernatant, rather than the neutral one, was regarded as the system blank for each illite suspension to yield the surface site concentrations. In order to describe the acid-base chemistry of aqueous illite surfaces, two surface proton-reaction models, introducing the corresponding reactions between the dissolved aluminum species and silicic acid, as well as a surface AI-Si complex on homogeneous illite surface sites, were proposed as follows:

(i) Model I,

$$
\begin{gathered}
\equiv \mathrm{SOH} \Leftrightarrow \equiv \mathrm{SO}^{-}+\mathrm{H}^{+}, \quad \mathrm{p} K_{\mathrm{a}}^{\mathrm{int}}=3.76-4.09, \\
\equiv \mathrm{SOH}+\mathrm{Al}^{3+}+\mathrm{H}_{4} \mathrm{SiO}_{4} \Leftrightarrow \equiv \mathrm{SOAI}\left(\mathrm{OSi}(\mathrm{OH})_{3}\right)^{+}+2 \mathrm{H}^{+}, \\
\quad \mathrm{p} K_{\mathrm{SC}}=3.06-3.53 ;
\end{gathered}
$$

(ii) Model II,

$$
\begin{gathered}
\mathrm{Al}^{3+}+\mathrm{H}_{4} \mathrm{SiO}_{4}+2 \mathrm{H}_{2} \mathrm{O} \Leftrightarrow \mathrm{Al}(\mathrm{OH})_{2}\left(\mathrm{OSi}(\mathrm{OH})_{3}\right)+3 \mathrm{H}^{+}, \\
\mathrm{p} K_{\mathrm{f} 2}=9.85-10.71, \\
\equiv \mathrm{SOH} \Leftrightarrow \equiv \mathrm{SO}^{-}+\mathrm{H}^{+}, \quad \mathrm{p} K_{\mathrm{a}}^{\mathrm{int}}=3.73-4.08, \\
\equiv \mathrm{SOH}+\mathrm{Al}^{3+}+\mathrm{H}_{4} \mathrm{SiO}_{4} \Leftrightarrow \equiv \mathrm{SOAI}\left(\mathrm{OSi}(\mathrm{OH})_{3}\right)^{+}+2 \mathrm{H}^{+}, \\
\mathrm{p} K_{\mathrm{SC}}=3.31-3.48 .
\end{gathered}
$$

The $K_{\mathrm{f} 2}$ constant in Model II was obtained by simulating the complex formation between the dissolved aluminum species and silicic acid that occurred in acidimetric supernatant when the hydroxide was added. Additionally, the following cation exchange reaction was also considered for a special case, where a large amount of $\mathrm{K}^{+}$is released during the corresponding acidimetric titration, in which a high concentration of protons are consumed.

$$
\equiv \mathrm{XH}+\mathrm{K}^{+} \Leftrightarrow \equiv \mathrm{XK}+\mathrm{H}^{+}, \quad \mathrm{p} K_{\mathrm{i}}=\mathbf{8 . 2 4}-\mathbf{8 . 5 2}
$$

\footnotetext{
${ }^{1}$ To whom correspondence should be addressed.
}

Optimization results indicated that both models could provide a good description of the titration behavior for all aqueous illite systems in this study. The intrinsic acidity constants for the different illites were similar in Model I, showing some generalities in their acid- base properties. Model I may be considered as a simplification of Model II, evident in the similarities between the corresponding constants. In addition, the formation constant for surface Al-Si species (complexes or precipitates) is relatively stable in this study. $\odot 1999$ Academic Press

Key Words: natural illites; acid- base properties; potentiometric titration; surface AI-Si complexation; constant capacitance model.

\section{INTRODUCTION}

Solid-water interfacial reactions, such as adsorption, dissolution, and precipitation, largely decide the fate of various contaminants in geochemical circulation. Therefore, the surface chemistry of complex natural particles, in which clay minerals are dominant components, is a current focus of interest (1-3). Over the past several decades, great developments have been achieved in this field, not only in the application and modification of various surface complexation models, such as the constant capacitance (CCM) (4-6), diffuse-layer (DLM) $(7,8)$, triple-layer $(9,10)$, and four-layer (FLM) (11) models, but also in the experimental methods and techniques for surface characterization, e.g., X-ray absorption and photoelectron spectroscopy, as well as scanning probe microscopy (12-14). To date, potentiometric titration is still an important method to study the surface properties of clay minerals and natural sediments. However, due to the differences in sample impurities and experimental conditions, such as equilibrium time, choice of zero point of titration (ZPT), titration procedure, and theoretical assumptions, published results and conclusions concerning surface reaction models of natural aqueous particles may differ, from case to case. Knowledge is therefore still deficient with respect to understanding the complexity in structure and composition of naturally occurring particles.

Illite, belonging to the mica group, is extensively distributed in the Earth's crust, and some works on different aspects of its behavior have been launched (15-17), e.g., electrochemical properties and adsorption of contaminants. In addition, the 
surface acid-base chemistry of illite was investigated at different ZPT values (18-20). When the ZPT was situated at a weak alkaline $\mathrm{pH}$, two equilibrium constants were obtained by employing the CCM, which included both protonation and deprotonation steps, i.e., $\mathrm{p} K_{\mathrm{a} 1}=9.30$ and $\mathrm{p} K_{\mathrm{a} 2}=10.43$ (18) or $\mathrm{p} K_{\mathrm{a} 1}=7.5$ and $\mathrm{p} K_{\mathrm{a} 2}=11.7(19)$, respectively. Another recent paper (20) successfully demonstrated the surface acid-base reactions of one aqueous illite using the CCM with only a deprotonation step, the proposed reaction constant of $\mathrm{p} K_{\mathrm{a}}=$ 4.23 being achieved at acidic ZPT. Since the solubility of aluminum from a $5 \mathrm{~g} /$ liter illite suspension, after $24 \mathrm{~h}$, appeared to be $\mathrm{pH}$ independent as indicated by leaching levels below 3 $\mathrm{mg} /$ liter at both $\mathrm{pH} 2.46$ and $\mathrm{pH} 8.75$, the influences of acidic dissolution, and subsequent precipitation, during the acid-base potentiometric titrations were neglected in the model evaluation of the back titration data. Nevertheless, the prolonged titration procedure in acidic medium requiring strict control of the equilibrium criterion (i.e., the drift in the measured potential should be lower than $1 \mathrm{mV} / \mathrm{h}$ ) may significantly enhance the release of aluminum. Additionally, many studies indicated that the presence of silicic acid can strongly influence the distribution of aluminum species in acidic environments, ranging from low-order soluble $\mathrm{Al}-\mathrm{Si}$ species, i.e., monomeric forms (21), to polymeric hydroxyaluminosilicates (22-25) and colloidal precipitates which were proposed as noncrystalline protoimogolite sols $(26,27)$ or mixtures of amorphous disordered aluminosilicates (28).

It is believed that polymeric hydroxyaluminosilicate (HAS) ions can readily form in significant amounts at ambient temperature over the $4-7 \mathrm{pH}$ range, when a mixture of $\mathrm{Al}$ and $\mathrm{Si}$ solutions are titrated with $\mathrm{NaOH}(27,29,30)$, but this procedure may be masked by the appearance of colloidal precipitates like protoimogolite sols. Soluble Al-Si species are intermediates in the weathering reactions of primary and secondary aluminosilicates in soils, geological formations, and surface waters, and they may affect the dissolution of solid aluminum silicates and serve as templates, or structural subunits, for secondary clay minerals (21). Furthermore, Farmer and Lumsdon (24) reported a unit shift of the formation constant for monomeric hydroxyl Al-Si species according to the reaction

$$
\mathrm{Al}^{3+}+\mathrm{H}_{4} \mathrm{SiO}_{4} \Rightarrow \mathrm{Al}\left(\mathrm{OSi}(\mathrm{OH})_{3}\right)^{2+}+\mathrm{H}^{+},
$$

their estimate of the $\mathrm{p} K$ value being $2.50 \pm 0.05$, compared with the value $1.07 \pm 0.06$ predicted by Browne and Driscoll (21). Later, Exley and Birchall (25), also confirmed this view by suggesting that the HAS species generated at $\mathrm{pH} 4.5$ and above have less important effects upon the distribution of aluminum speciation.

As for the related formation mechanism, some researchers suggested that aluminum species could combine with (ortho)silicic acids through condensation reactions between the aluminol and silanol groups to generate HAS ions (29); others presumed that silicic acid could poison or inhibit the nucleation of aluminum hydroxides by replacing hydroxylated aluminum at growth sites on solid $\mathrm{Al}(\mathrm{OH})_{3}$ lattices $(22,31)$, in which the formation rate was dependent upon both the solution $\mathrm{pH}$ and the silicic acid concentration. Another interpretation assumed that substitution of silicic acid for water molecules occurred inside the inner coordination sphere of hexa-aqua aluminum species (21). Moreover, Fitzgerald et al. (28) supposed that aluminate species, converted from hexaaqua octahedral $\mathrm{Al}$ by addition of $\mathrm{NaOH}$, were inserted into oligomeric or low molecular weight silicates to form soluble and insoluble polymeric aluminosilicates, such as colloidal hydrosol precipitates other than $\mathrm{Al}(\mathrm{OH})_{3}$, based on the experimental data of solid state ${ }^{29} \mathrm{Si} /{ }^{27} \mathrm{Al} \mathrm{NMR}$.

The studies mentioned above were mainly focused on the processes occurring in synthetic or natural solutions. However, the influence of natural complex particles, present as the matrix or reaction phase which frequently takes part in various surface reactions in aquatic systems, is neglected. On the other hand, some papers have described investigations of the association of soluble aluminum ionic species with solid silica gel surfaces in lower $\mathrm{pH}$ regions and have indicated that the $\mathrm{Al}$ cations left in solution interacted with the aqueous $\mathrm{Si}$ species, leading with time to the formation of a metastable silica-aluminum dispersed solid phase $(32,33)$.

In order to acquire more details on acid-base properties at illite surface binding sites, which are critical for quantitative description of other sorption processes, such effects should be considered in model simulations. A comparative study, concerning naturally occurring illite samples collected from different locations, would be conducive to obtaining a comprehensive understanding of adsorption, dissolution, and precipitation, as well as to unraveling some possible uncertainties presented in specific cases. Furthermore, a unified thermodynamic model can be set up to describe the general behavior of surface acid-base properties over a group of illitic minerals, and the CCM, with its corresponding approximations and assumptions, may be a preferable choice due to its simplicity and practicality.

The major purposes of this study, as a continuation of our previous work (20), are twofold. The first is to develop the understanding of the surface acid-base chemistry of natural illites by comparison of the behavior of several different materials during potentiometric titrations. The second is to further examine the applicability of the CCM for characterizing the reaction mechanisms for greater fidelity, while considering the corresponding dissolution and possible surface complexation or precipitation, probably formed by the interactions between aluminum species and silicic acid.

\section{MATERIALS AND METHODS}

\section{Materials}

The solid samples were gathered from three sources: (1) WeiChang illite (Permian period) in HeBei Province, northern 
TABLE 1

Chemical Composition of Each Illite Solid (Mean \pm One Standard Deviation)

\begin{tabular}{|c|c|c|c|}
\hline Components & WeiChang (WC) & LiuPanShui (LPS) & Williams Town (WT) \\
\hline $\mathrm{SiO}_{2}(\%)$ & $72.5 \pm 0.2$ & $64.7 \pm 0.1$ & $55.7 \pm 0.3$ \\
\hline $\mathrm{Al}_{2} \mathrm{O}_{3}(\%)$ & $14.9 \pm 0.2$ & $15.6 \pm 0.1$ & $28.9 \pm 0.5$ \\
\hline $\mathrm{CaO}(\%)$ & $0.500 \pm 0.036$ & $0.495 \pm 0.014$ & $<0.0931$ \\
\hline $\mathrm{Fe}_{2} \mathrm{O}_{3}(\%)$ & $2.55 \pm 0.01$ & $1.34 \pm 0.01$ & $0.800 \pm 0.005$ \\
\hline $\mathrm{K}_{2} \mathrm{O}(\%)$ & $4.13 \pm 0.09$ & $6.78 \pm 0.02$ & $6.90 \pm 0.18$ \\
\hline $\mathrm{MgO}(\%)$ & $1.32 \pm 0.02$ & $5.22 \pm 0.02$ & $0.360 \pm 0.009$ \\
\hline $\mathrm{MnO}_{2}(\%)$ & $0.0713 \pm 0.0002$ & $0.0047 \pm 0.0004$ & $0.0048 \pm 0.008$ \\
\hline $\mathrm{Na}_{2} \mathrm{O}(\%)$ & $0.559 \pm 0.017$ & $0.0755 \pm 0.0040$ & $0.887 \pm 0.029$ \\
\hline $\mathrm{P}_{2} \mathrm{O}_{5}(\%)$ & $0.0868 \pm 0.0022$ & $0.123 \pm 0.002$ & $0.0572 \pm 0.0036$ \\
\hline $\mathrm{TiO}_{2}(\%)$ & $0.366 \pm 0.002$ & $0.256 \pm 0.001$ & $1.05 \pm 0.01$ \\
\hline BET surface area ${ }^{a}\left(\mathrm{~m}^{2} / \mathrm{g}\right)$ & $25.15 \pm 0.14$ & $49.19 \pm 0.27$ & $19.04 \pm 0.05$ \\
\hline BET surface area ${ }^{b}\left(\mathrm{~m}^{2} / \mathrm{g}\right)$ & $26.19 \pm 0.21$ & $53.40 \pm 0.03$ & $19.01 \pm 0.11$ \\
\hline$d(001)$ spacing $(\AA)$ & 9.99 & 9.90 & 9.91 \\
\hline
\end{tabular}

\footnotetext{
${ }^{a}$ Surface area of particles in neutral suspensions.
}

${ }^{b}$ Surface area of particles in acidic suspensions.

China; (2) LiuPanShui illite (Cretaceous period) in GuiZhou Province, southern China; and (3) Williams Town illite (late Proterozoic period) in southern Australia (hereafter abbreviated to WC, LPS, and WT, respectively). The primary samples were ground and sieved to less than $53-\mu \mathrm{m}$ fractions. Stock suspensions of $20 \mathrm{~g} /$ liter were prepared individually and stored in the refrigerator at $4^{\circ} \mathrm{C}$. There was no further pretreatment, except for equilibration in aqueous suspension for at least 2 weeks prior to the experiments.

Elemental compositions of the raw solids were determined using inductively coupled plasma-optical emission spectrometry (ICP-OES, ARL Model 3580). The average values of the layer distance in the crystal structure and the external surface area were measured by X-ray powder diffraction (Siemens D5000 diffractometer, $\mathrm{Cu} K \alpha$ radiation) and by the $\mathrm{N}_{2} / \mathrm{BET}$ method (Micrometrics, ASAP Model 2000), respectively. All results are summarized in Table 1 . In addition, scanning electron microscope images showed that the illite particles appeared as plate-like crystals, configurated in stacks (see Fig. 1).

\section{Solubility of Illite Suspensions at Various pH}

The solubility test was implemented in batch systems. Each sample consisted of a $5 \mathrm{~g} /$ liter illite suspension, to which an increment of $\mathrm{HNO}_{3}$ or $\mathrm{NaOH}$ was added to adjust the $\mathrm{pH}$ between 2 and 10. In addition, a $10 \mathrm{~g} /$ liter suspension without $\mathrm{acid} / \mathrm{base}$ addition was also made for each illite sample. No background electrolyte was used for the samples mentioned above. All the slurries were shaken at room temperature for $24 \mathrm{~h}$. Then, every illite sample was analyzed for final $\mathrm{pH}$ under stirring and filtered through a $0.45-\mu \mathrm{m}$ membrane (Schleicher $\&$ Schuell Filter). ICP-OES was utilized to quantify $\mathrm{Ca}, \mathrm{Si}, \mathrm{Al}$, $\mathrm{K}, \mathrm{Mg}$, and $\mathrm{Fe}$ in each filtrate.

\section{Determination of Carbonate in Illite}

Total inorganic carbonate in illite samples was determined automatically, after conversion to carbon dioxide following addition of excess strong acid, by photoacoustic spectroscopy (Gas Analyzer Type 1301, Brüel \& Kjær A/S). After background compensation and span calibration, a 50-ml suspension, containing $1 \mathrm{~g}$ solid, was purged with pure $\mathrm{N}_{2}$ for $15 \mathrm{~min}$ to ensure that the residual $\mathrm{CO}_{2}$ was below $4 \mathrm{ppm}$. Thereafter, the $\mathrm{N}_{2}$ flow was arrested, acid was injected and the concentration of $\mathrm{CO}_{2}$ generated by the solid was recorded until equilibrium was achieved. As calibration was performed using calcite as standard substance, all results are presented in terms of the calcite concentration in each illite sample.

\section{Potentiometric Titration of Various Illite Suspensions}

A back titration procedure with two sequential steps, i.e., acidimetric and alkalimetric titrations, was used. The sample suspension was firstly acidified to about $\mathrm{pH} 3$, then back titrated with hydroxide to the alkaline region.

For precise electromotive force (e.m.f.) titrations, we employed an automatic system in which the reactor, equipped with a glass electrode in conjunction with a double junction $\mathrm{Ag} / \mathrm{AgCl}$ reference electrode, was immersed in an oil thermostat bath at $25.0 \pm 0.5^{\circ} \mathrm{C} \mathrm{(34).} \mathrm{Standard} 0.1 \mathrm{M} \mathrm{HNO}_{3}$, in $0.1-\mathrm{ml}$ increments, was added to $50 \mathrm{ml}$ of $10 \mathrm{~g} /$ liter illite suspension in $0.1 \mathrm{M} \mathrm{NaNO}_{3}$ medium. When the suspension $\mathrm{pH}$ became lower than 3, the following back titration started with the addition of standard $0.05 \mathrm{M} \mathrm{NaOH}$, in increments of $0.1 \mathrm{ml}$, until the $\mathrm{pH}$ exceeded 10. During the whole procedure, the equilibrium criterion was that the drift in the measured potential should be below $1 \mathrm{mV} / \mathrm{h}$, while continuous purging with pure $\mathrm{N}_{2}$ occurred and magnetic stirring was applied. The equilibrium concentration of $\mathrm{H}^{+}$was derived from the output of the glass 
a

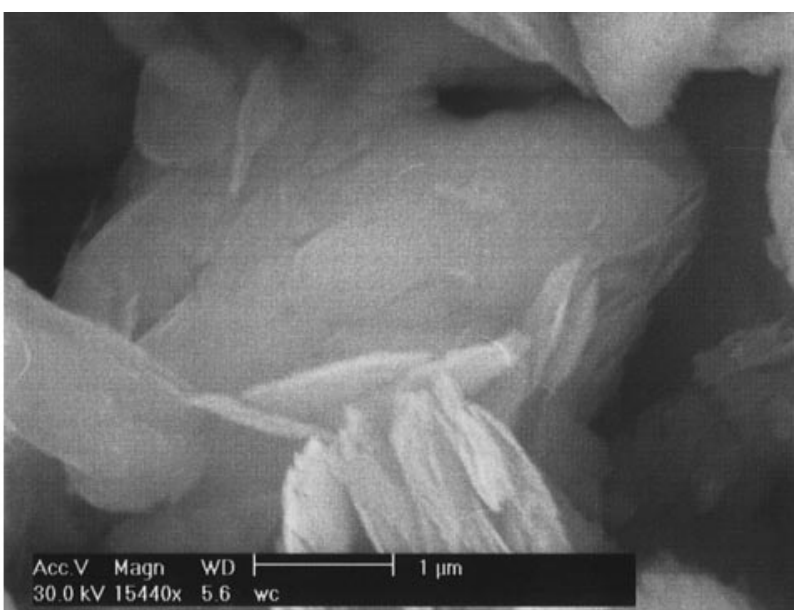

b

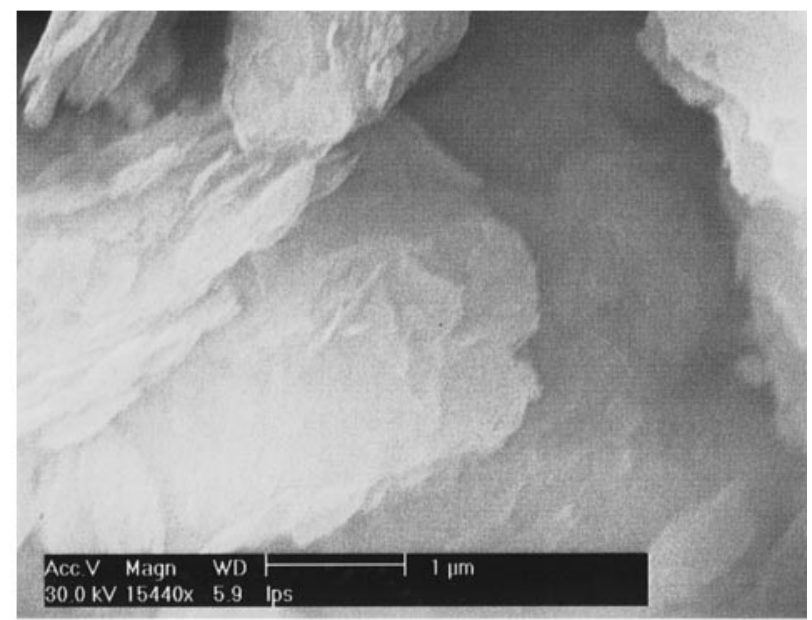

C

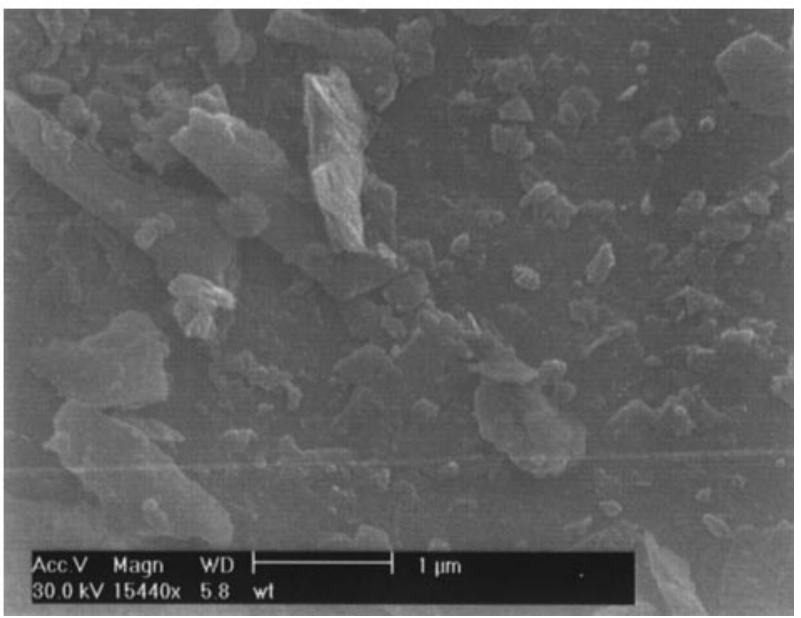

FIG . 1. Scanning electronic microscopy image for each illite: (a) WC, (b) LPS, and (c) WT $(<53 \mu \mathrm{m}$, scale bar $=1 \mu \mathrm{m})$.

electrode, according to the Nernst equation. In the special case of WT illite, due to its strong acid buffer capability, a final $\mathrm{pH}$ close to 4 in the acidimetric titration was adopted, the related details being discussed in the relevant results section.
The neutral and acidimetric supernatants were prepared from the initial suspension and the acidic one, respectively, following centrifugation at $20,000 \mathrm{rpm}$ at $10^{\circ} \mathrm{C}$ for $30 \mathrm{~min}$. In addition to performance of identical back titrations, their chemical compositions were then determined by ICP-OES.

\section{RESULTS AND DISCUSSION}

\section{Solubility of Aqueous Illites}

As a whole, the results of solubility tests for the three aqueous illites in the range from $\mathrm{pH} 2$ to $\mathrm{pH} 10$ are in agreement with findings reported in the previous paper (20). Unlike the $\mathrm{pH}$-dependent labile elements, such as $\mathrm{Ca}, \mathrm{K}$, and $\mathrm{Mg}$, the detachment of $\mathrm{Si}$ appeared to be insensitive to the $\mathrm{pH}$ change during $24 \mathrm{~h}$, whereas the trend of increasing $\mathrm{Al}$ release, toward the extremes of the acidic and alkaline regions, reflects its amphoteric properties. As no constant leaching ratio between $\mathrm{Si}$ and $\mathrm{Al}$ was obtained, the dissolution of three illite samples over $24 \mathrm{~h}$ is still incongruent. It should be noted that, during the prolonged acidimetric titration, remarkable increases in dissolution with respect to that in the neutral supernatant resulted (see Fig. 2). This condition was also corroborated by comparison of the corresponding results shown as Gran plots (see Figs. 3c and 3d) and in titration curves (see Fig. 4), which exhibited some significant differences between the two types of supernatant. Furthermore, a dispersed solid phase could be visually observed in all acidimetric supernatants during the back titration, while none was seen in the neutral ones. Thus, regarding the acidimetric supernatant as the system blank is more reasonable, a view also expressed in another similar study (35).

\section{In Situ Gran Plot Method}

In situ Gran plots $(20,36)$ were utilized here to determine the specific volume of titrant added at the equivalence point $\left(V_{\mathrm{e}}\right)$ and to derive the standard electrode potential $\left(E^{0}\right.$ in $\left.\mathrm{mV}\right)$ for the selected titration systems.

The related equivalence points, in the acidimetric titration ( $V_{\text {ea }}$ in Fig. 3a) and the alkalimetric back titrations ( $V_{\text {eb } 1}$ and $V_{\mathrm{eb} 2}$ in Figs. 3b-3d), were calculated from the results of linear regression analysis of the Gran plots. Accordingly, the $E^{0}$ value of the corresponding titration could be calculated to convert the e.m.f. output of the glass electrode into a $\mathrm{pH}$ value, i.e., $-\log \left[\mathrm{H}^{+}\right]$.

In our study, similar behavior, e.g., Gran plots (exemplified by LPS illite in Fig. 3) and titration curves in Figs. 4a and 4b, was obtained for the two illite samples from China. However, it is not possible to ascertain the $E^{0}$ for the WT illite using the Gran plot due to the large buffer capacity of this sample (see Fig. 4c). Therefore, another means of $E^{0}$ calibration was employed, on the basis of linear regression analysis of a set of potential values and corresponding records of $-\log \left[\mathrm{H}^{+}\right](37)$. 


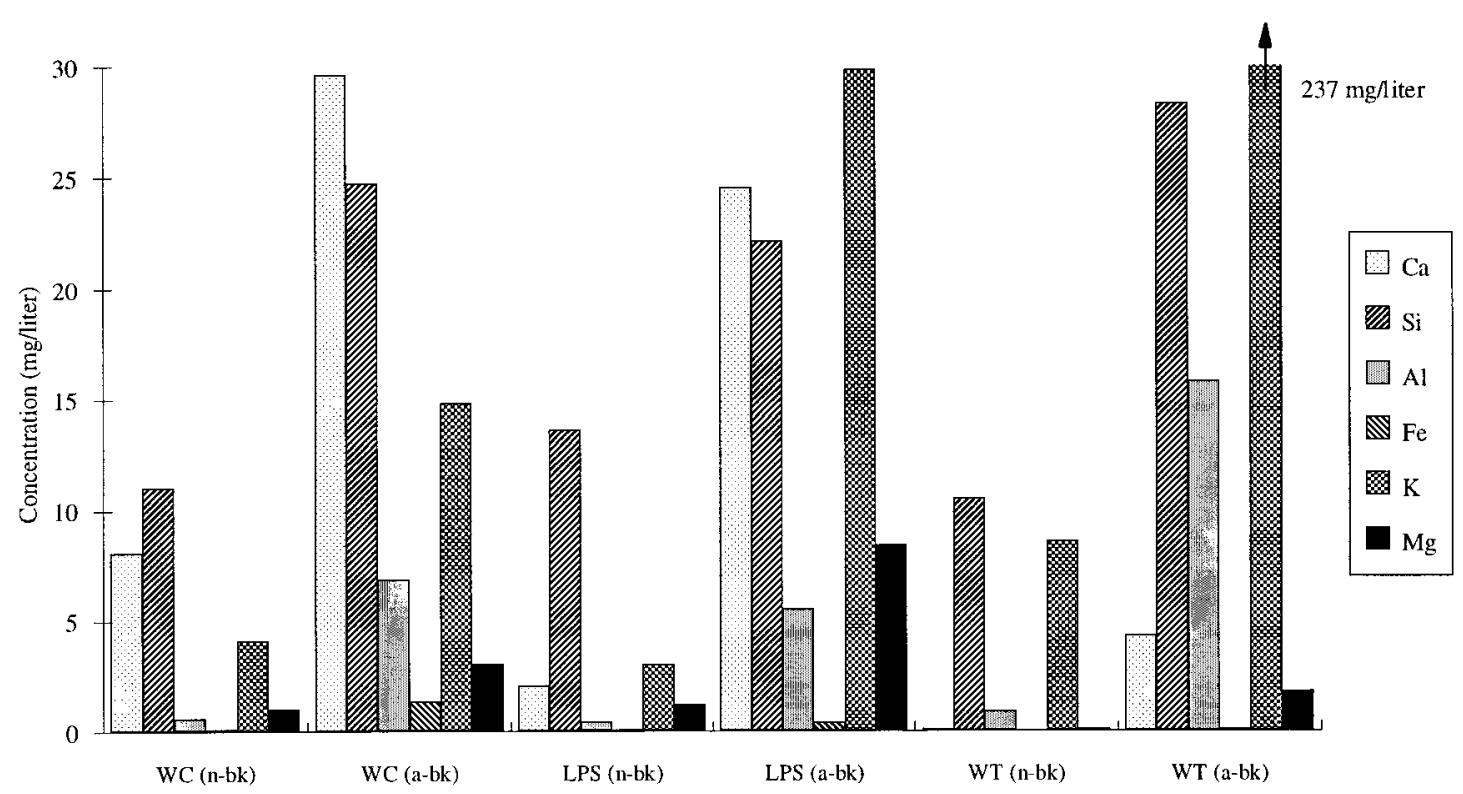

FIG. 2. Comparison of element release between neutral and acidimetric supernatants. Here, n-bk and a-bk denote neutral and acidimetric system blanks, respectively.

\section{Protons Consumed by Carbonate in Illite}

In natural clay minerals, carbonate is a common proton-consuming component that may cause errors in the estimation of the surface acid-base properties from the results of potentiometric titrations $(20,38,39)$. For instance, an overestimation of the surface site density will be made if no consideration is given to the consumption of protons by carbonate. This problem could be reflected by differences in curve forms between the acidimetric and the alkalimetric titrations. In this study, total inorganic carbonate, in the form of the calcite amount given by the gas analyzer, was determined to be 5.73, 0.85, and $3.70 \mathrm{mg} \mathrm{CaCO}_{3} / \mathrm{g}$, respectively, in samples of WC, LPS, and WT illite.

\section{Determination of the Zero Point of Titration (ZPT)}

According to the Gran plots presented above, the added hydroxide ions successively participated in the following processes (20), interaction with excess $\mathrm{H}^{+}$(before $V_{\text {eb1 } 1}$ ), binding to the various $\mathrm{OH}^{-}$acceptors on the illite surfaces in suspension (between $V_{\mathrm{eb} 1}$ and $V_{\mathrm{eb} 2}$ ), and contribution to the system $\mathrm{pH}$ (after $V_{\mathrm{eb} 2}$ ). Consequently, $V_{\mathrm{eb} 1}$ in Fig. $3 \mathrm{~b}$ was regarded as the ZPT, since only acid-base neutralization occurred in solution phase before this point. The total concentration of reacted protons in each titration point, denoted TOTH, was therefore estimated by the equation

$$
\text { TOTH }=\frac{-\left(V_{\mathrm{b}}-V_{\mathrm{eb} 1}\right) \times C_{\mathrm{b}}}{V_{0}+V_{\mathrm{at}}+V_{\mathrm{b}}}(\mathrm{mol} / \mathrm{liter}),
$$

where $V_{\text {at }}$ is the total volume of $\mathrm{HNO}_{3}$ added during the acidimetric titration, $V_{\mathrm{b}}$ denotes the volume of $\mathrm{NaOH}$ added in the alkalimetric titration, and $V_{0}$ and $C_{\mathrm{b}}$ represent the initial volume of the suspension and the concentration of $\mathrm{NaOH}$, respectively. After ZPT calibration, the hydroxide back titration values were used as input data for analysis by the FITEQL program, Version 2.0 (40). As for WT illite, it was similarly calibrated in the corresponding acidic region by adjusting the input value of total protons defined in the chemical equilibrium program.

At each titration point, the amount of protons consumed by all surface sites $\left(H_{\mathrm{R}}\right)$ is computed using

$$
\begin{aligned}
H_{\mathrm{R}}=\left[\mathrm{TOTH}-10^{-\mathrm{pH}}+10^{-\left(\mathrm{p} K_{\mathrm{w}}-\mathrm{pH}\right)}\right] & \\
& \times\left(V_{0}+V_{\mathrm{at}}+V_{\mathrm{b}}\right)(\mathrm{mol}),
\end{aligned}
$$

where, $\mathrm{pH}$ and $K_{\mathrm{W}}$ denote the $-\log \left[\mathrm{H}^{+}\right]$and ionic product of water in $0.1 \mathrm{M}$ medium, respectively.

\section{Calculation of Surface Site Concentration $\left(H_{S}\right)$}

Based on the aforementioned assignment of added hydroxide ions, we further calculated $H_{\mathrm{S}}$ using the acidimetric supernatant as the system blank rather than the neutral one. The formula is as follows:

$$
H_{\mathrm{S}}=\frac{\left(V_{\mathrm{eb} 2}-V_{\mathrm{eb} 1}\right)_{\mathrm{sample}} \times C_{\mathrm{b}}-\left(V_{\mathrm{eb} 2}-V_{\mathrm{eb} 1}\right)_{\mathrm{blank}} \times C_{\mathrm{b}}}{V_{0}}
$$

(mol/liter).

In the particular case of WT illite, the surface site concentration was primarily treated as an adjustable parameter and 

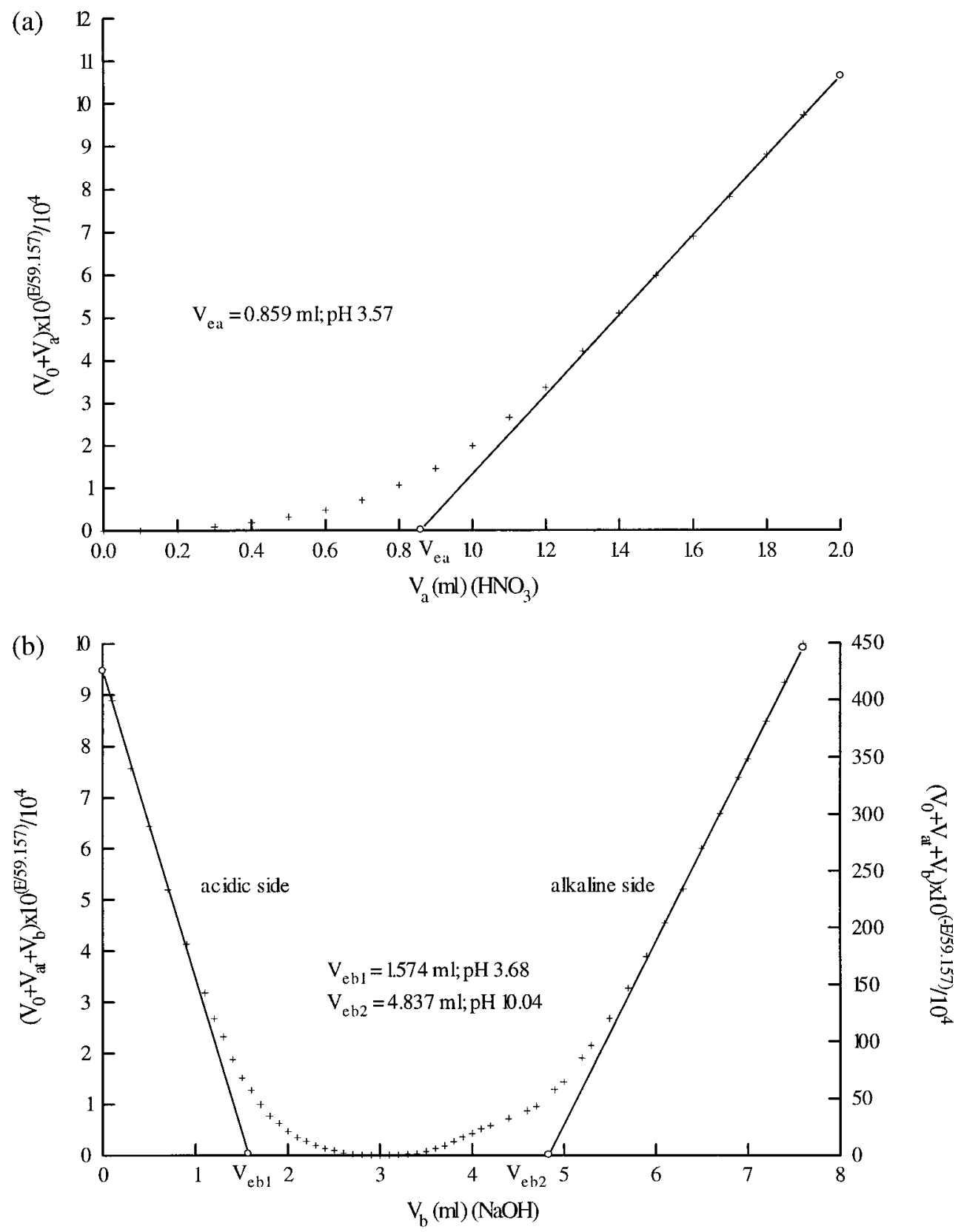

FIG. 3. In situ Gran plots for titrations of LPS illite suspension. In (a), the results of the acidimetric titration are depicted. Hydroxide back titration data for (b) the sample suspension, (c) the acidimetric supernatant, and (d) the neutral supernatant are also shown.

optimized by FITEQL, since it could not be derived using Eq. [3].

\section{Surface Acid-Base Reaction Models}

1. System blank. The corresponding acidity constants of $\mathrm{Al}^{3+}$ and $\mathrm{Si}(\mathrm{OH})_{4}$ in aqueous solution (41) are summarized in Table 2. In this study, the proton reactions in the illite suspension supernatants were described by those of $\mathrm{Si}(\mathrm{OH})_{4}$ and $\mathrm{Al}^{3+}$ in aqueous solution, similar to the previous paper (20), since natural illite is mainly composed of hydrous aluminosilicate.
However, strong evidence indicated that total concentrations of silicon (TOT( $\mathrm{Si})$ ) and aluminum (TOT(Al)) in the acidimetric supernatant, changed significantly relative to the levels in the neutral supernatant (Fig. 2); some apparent differences could be distinguished in the titration curves as well (see Figs. $3 \mathrm{c}$ and $3 \mathrm{~d}$ and Fig. 4). The general effect of taking the neutral supernatant as the system blank would be an overestimation of proton consumption by the solid surface. Therefore, the analytical data, obtained using ICP-OES in the acidimetric supernatant, were selected as the FITEQL inputs when we modeled 

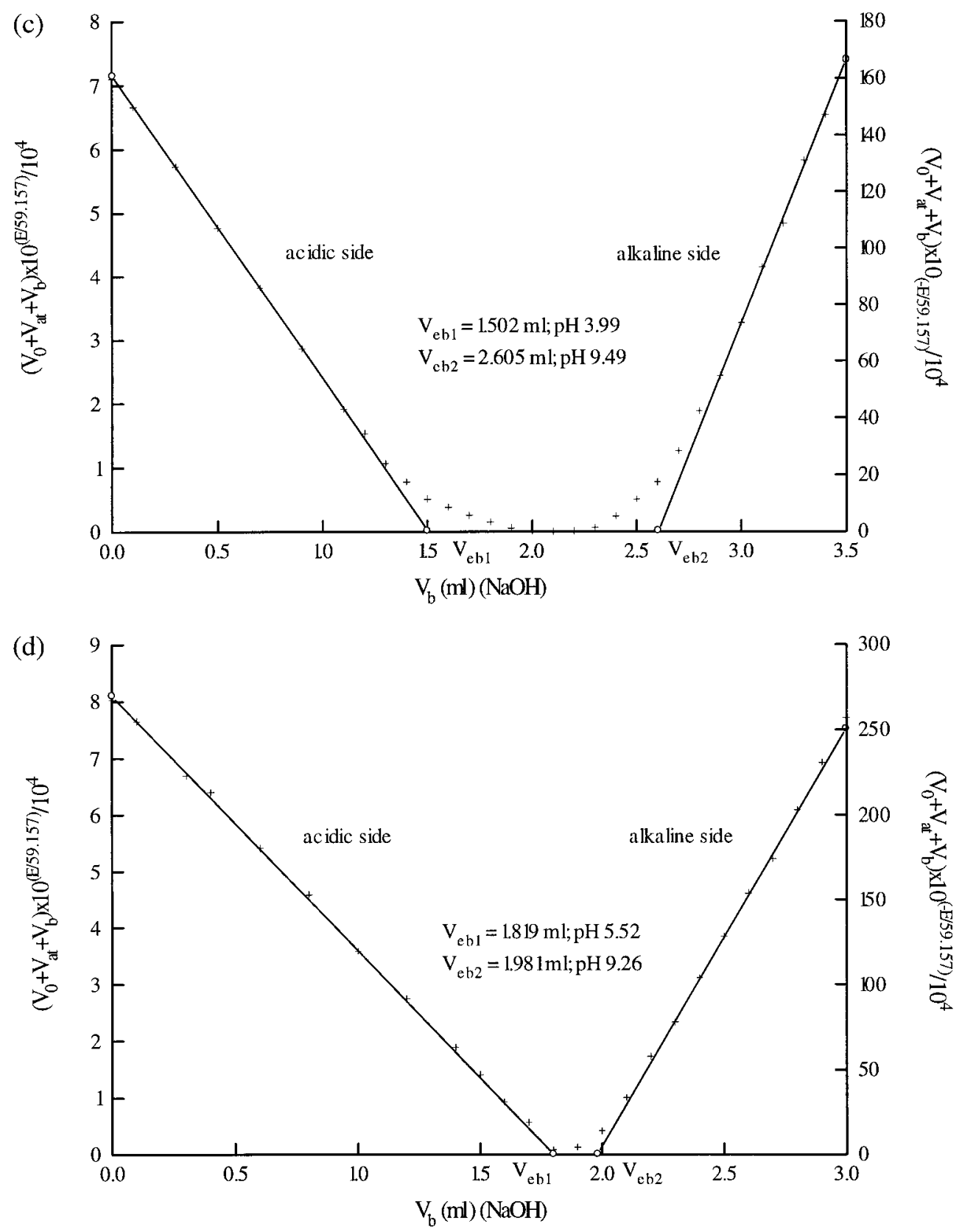

FIG. 3-Continued

the back titration behavior of these illite suspensions. Data pertaining to the acidimetric supernatant of each illite suspension were fairly difficult to fit by FITEQL, which is ascribable to the occurrence of bulk precipitation during the follow-up back titration. Based on actual measurements in acidimetric supernatants (see Fig. 2), the influence of silicic acid, originating from acidic dissolution of illite samples, should be taken into account, due to formation of various HAS species with dissolved aluminum species. Some proposed interpretations for the corresponding formation mechanism involved condensation reactions between the aluminol and sila- nol groups (29) and inhibition of $\mathrm{Al}(\mathrm{OH})_{3}$ lattice growth or nucleation $(22,31)$, as well as molecular substitution of silicic acid for water in the inner coordination sphere of the hexaaqua $\mathrm{Al}$ species (21) or insertion of aluminate species into oligomeric or low molecular weight silicates (28). Therefore, the complex formation of various HAS species during the alkalimetric titration for the aqueous illites should be considered as well.

The general stoichiometry of Al-Si could be evaluated according to the reaction series, allowing for the formation of mixed hydroxyaluminosilicates, 
(a)

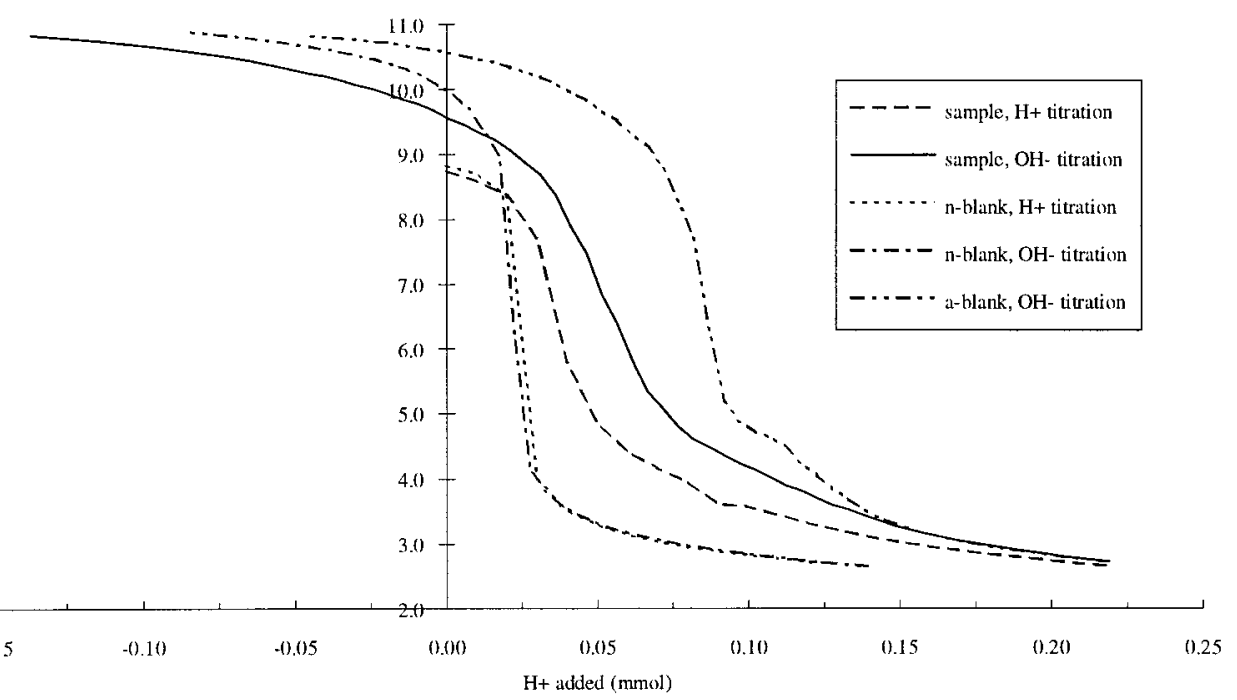

(b)

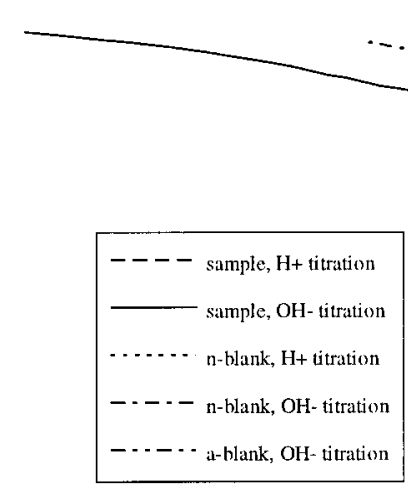

I

H+ added (mmol)

0.25

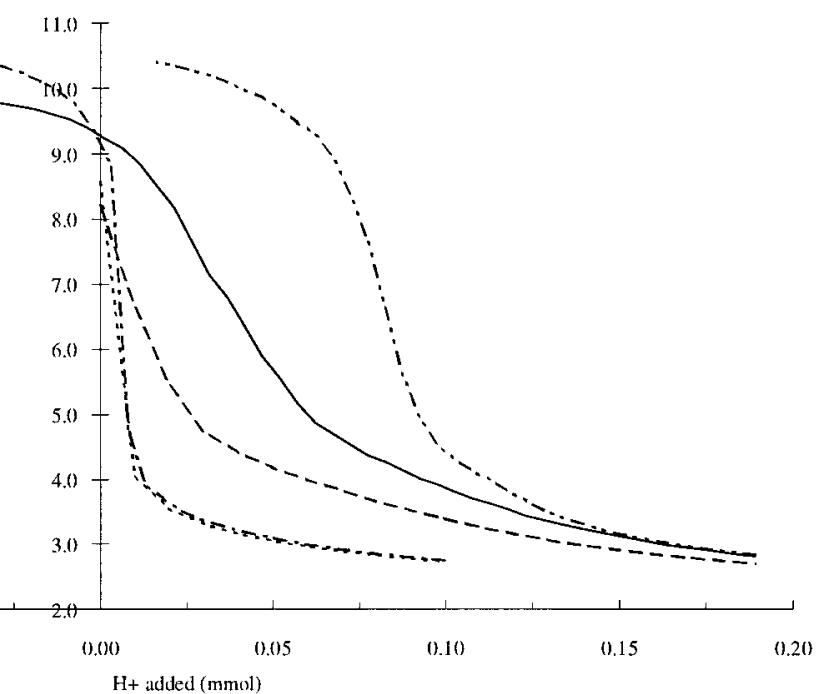

(c)

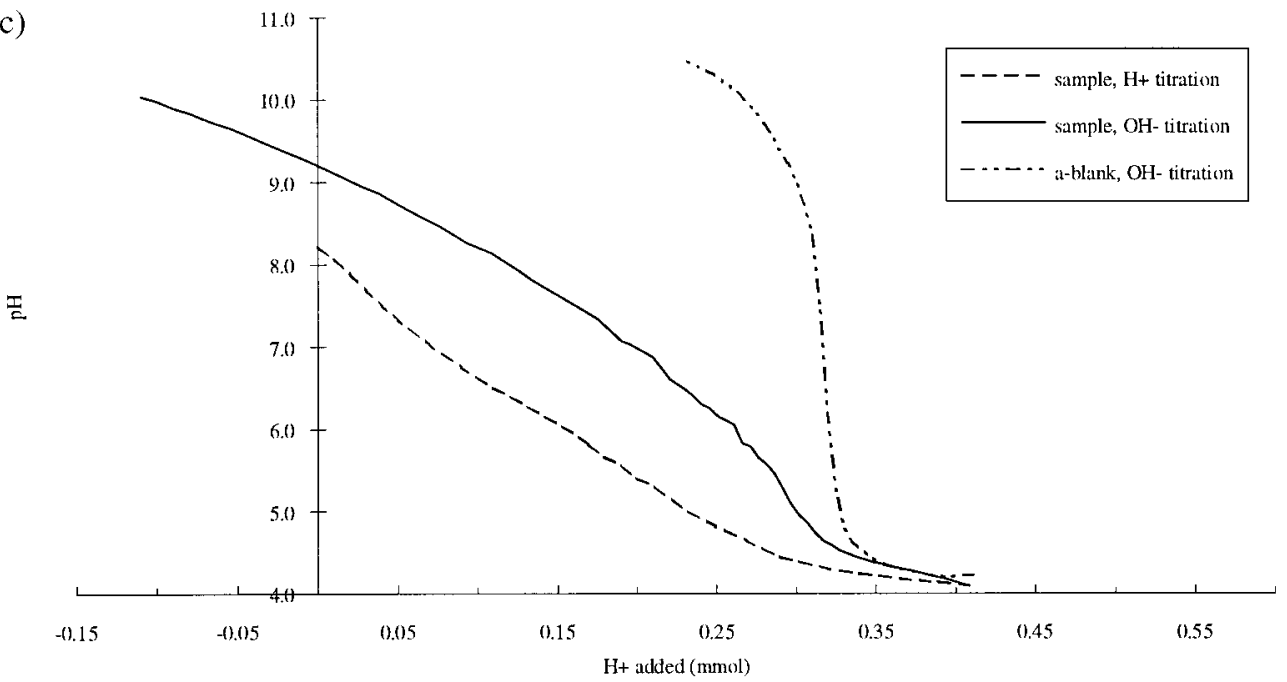

FIG . 4. Titration curves for different illite suspensions (all $10 \mathrm{~g} /$ liter, $0.1 \mathrm{M} \mathrm{NaNO}_{3}$ ) and their corresponding supernatants: (n-blank) neutral blank, (a-blank) acidimetric blank, (a) WC illite, (b) LPS illite, (c) WT illite. 
TABLE 2

Model Optimization and Analytical Results for the Neutral and Acidimetric Supernatants of Illite Suspensions

Reaction constants of $\mathrm{Al}^{3+}$ and $\mathrm{Si}(\mathrm{OH})_{4}$ in aqueous solution (41) as the parameters used by FITEQL

$$
\begin{aligned}
& \mathrm{Al}^{3+}+\mathrm{H}_{2} \mathrm{O}\Leftrightarrow \mathrm{AlOH})^{2+}+\mathrm{H}^{+} \\
& \mathrm{Al}^{3+}+2 \mathrm{H}_{2} \mathrm{O} \Leftrightarrow \mathrm{Al}(\mathrm{OH})_{2}^{+}+2 \mathrm{H}^{+} \\
& \mathrm{Al}^{3+}+3 \mathrm{H}_{2} \mathrm{O} \Leftrightarrow \mathrm{Al}(\mathrm{OH})_{3}+3 \mathrm{H}^{+} \\
& \mathrm{Al}^{++}+4 \mathrm{H}_{2} \mathrm{O} \Leftrightarrow \mathrm{Al}(\mathrm{OH})_{4}^{-}+4 \mathrm{H}^{+} \\
& \mathrm{Al}^{3+}+\mathrm{H}_{4} \mathrm{SiO}_{4} \Leftrightarrow \mathrm{Al}\left(\mathrm{OSi}(\mathrm{OH})_{3}\right)^{2+}+\mathrm{H}^{+} \\
& \mathrm{Al}^{3+}+\mathrm{H}_{4} \mathrm{SiO}_{4}+2 \mathrm{H}_{2} \mathrm{O} \Leftrightarrow \mathrm{Al}(\mathrm{OH})_{2}\left(\mathrm{OSi}(\mathrm{OH})_{3}\right)+3 \mathrm{H}^{+} \\
& \mathrm{Si}(\mathrm{OH})_{4} \Leftrightarrow \mathrm{SiO}(\mathrm{OH})_{3}^{-}+\mathrm{H}^{+} \\
& \mathrm{Si}(\mathrm{OH})_{3}^{-} \Leftrightarrow \mathrm{SiO}(\mathrm{OH})_{2}^{2^{-}}+2 \mathrm{H}^{+}
\end{aligned}
$$

\author{
$\log K=-5.52\left(25^{\circ} \mathrm{C}, I=0.1\right)$ \\ $\log K=-10.40\left(25^{\circ} \mathrm{C}, I=0.1\right)$ \\ $\log K=-16.30\left(25^{\circ} \mathrm{C}, I=0.1\right)$ \\ $\log K=-23.00\left(25^{\circ} \mathrm{C}, I=0.0\right)$ \\ $\log K_{\mathrm{f} 1}=-2.74 \pm 0.023(44)$ \\ $\mathrm{p} K_{\mathrm{f} 2}$, optimized by FITEQL program \\ $\log K=-9.46\left(25^{\circ} \mathrm{C}, I=0.5\right)$ \\ $\log K=-22.02\left(25^{\circ} \mathrm{C}, I=0.5\right)$
}

$p \mathrm{Al}^{3+}+q \mathrm{H}_{4} \mathrm{SiO}_{4}+r \mathrm{H}_{2} \mathrm{O} \Leftrightarrow$

$$
\mathrm{Al}_{p}(\mathrm{OH})_{r}\left(\mathrm{OSi}(\mathrm{OH})_{3}\right)_{q}^{3 p-q-r}+(q+r) \mathrm{H}^{+},
$$

where $p, q$, and $r$ are stoichiometric coefficients.

For simplicity, we mainly considered the simple pattern, i.e., low-order monomeric hydroxyl aluminosilicate $(p=1, r>$ $1)$, in this study.

$$
\mathrm{Al}^{3+}+\mathrm{H}_{4} \mathrm{SiO}_{4} \Leftrightarrow \mathrm{Al}\left(\mathrm{OSi}(\mathrm{OH})_{3}\right)^{2+}+\mathrm{H}^{+}, \quad \mathrm{p} K_{\mathrm{f} 1}
$$

Some reported values, in terms of $-\log K_{\mathrm{fl}}$, are $1.07 \pm 0.06$ (21), $2.50 \pm 0.05$ (24), and $2.38 \pm 0.10$ (43). Meanwhile,
Sjöberg et al. (44) recommended another estimate based on actual potentiometric titration measurements, i.e., $2.74 \pm 0.023$ for the formation of the $\mathrm{Al}\left(\mathrm{OSi}(\mathrm{OH})_{3}\right)^{2+}$ species. In this study,

\begin{tabular}{|c|c|c|c|c|c|c|c|c|c|}
\hline & $\begin{array}{c}H_{\mathrm{S}} \\
\left(\times 10^{-3} \mathrm{M}\right)\end{array}$ & $\begin{array}{c}C \\
\left(\mathrm{~F} / \mathrm{m}^{2}\right)\end{array}$ & $\mathrm{p} K_{\mathrm{a}}^{\mathrm{int}}$ & ${ }^{\sigma} \mathrm{p} K_{\mathrm{a}}^{\mathrm{int}}$ & $\mathrm{p} K_{\mathrm{SC}}$ & ${ }^{\sigma} \mathrm{p} K_{\mathrm{SC}}$ & $\mathrm{p} K_{\mathrm{i}}$ & ${ }^{\sigma} \mathrm{p} K_{\mathrm{i}}$ & $V_{\mathrm{Y}}$ \\
\hline \multicolumn{10}{|c|}{ WC illite, $C_{\mathrm{S}}=10 \mathrm{~g} /$ liter, $I=0.1 \mathrm{M} \mathrm{NaNO}_{3}, S^{a}=26.19 \mathrm{~m}^{2} / \mathrm{g}, D_{\mathrm{S}}^{b}=3.2$ sites $\mathrm{nm}^{-2}$} \\
\hline Model $1^{c}$ & 1.38 & 1.2 & 3.76 & 0.021 & 3.17 & 0.031 & - & - & 14.18 \\
\hline Model $2^{d}$ & 1.38 & 1.2 & 3.73 & 0.021 & 3.31 & 0.034 & - & - & 9.52 \\
\hline \multicolumn{10}{|c|}{ LPS illite, $C_{\mathrm{S}}=10 \mathrm{~g} /$ liter, $I=0.1 \mathrm{M} \mathrm{NaNO}_{3}, S^{a}=53.40 \mathrm{~m}^{2} / \mathrm{g}, D_{\mathrm{S}}^{b}=2.5$ sites nm${ }^{-2}$} \\
\hline Model $1^{c}$ & 2.20 & 0.8 & 4.09 & 0.015 & 3.06 & 0.030 & - & - & 23.41 \\
\hline Model $2^{d}$ & 2.20 & 0.8 & 4.06 & 0.014 & 3.40 & 0.042 & - & - & 14.42 \\
\hline \multicolumn{10}{|c|}{ WT illite, $C_{\mathrm{s}}=10 \mathrm{~g} /$ liter, $I=0.1 \mathrm{M} \mathrm{NaNO}_{3}, S^{a}=19.01 \mathrm{~m}^{2} / \mathrm{g}, D_{\mathrm{s}}^{b}=11.3$ sites nm$^{-2}$} \\
\hline Model $1^{e}$ & 9.63 & 13.5 & 4.02 & 0.007 & 3.60 & 0.027 & - & - & 17.10 \\
\hline Model $2^{e}$ & 9.63 & 13.5 & 4.05 & 0.007 & 3.56 & 0.030 & - & - & 22.97 \\
\hline Model $1^{c}$ & 9.63 & 13.5 & 4.04 & 0.008 & 3.53 & 0.028 & 8.52 & 0.046 & 15.27 \\
\hline Model $2^{d}$ & 9.63 & 13.5 & 4.08 & 0.007 & 3.47 & 0.030 & 8.24 & 0.031 & 17.48 \\
\hline
\end{tabular}
we adopted this value due to the similar experimental method.

In addition to the proton reactions of aqueous $\mathrm{Al}$ and $\mathrm{Si}$ listed in Table 2, we further employed an assumed reaction to simulate the corresponding aluminosilicate reaction process,

$$
\mathrm{Al}^{3+}+\mathrm{H}_{4} \mathrm{SiO}_{4}+2 \mathrm{H}_{2} \mathrm{O} \Leftrightarrow
$$

$$
\mathrm{Al}(\mathrm{OH})_{2}\left(\mathrm{OSi}(\mathrm{OH})_{3}\right)+3 \mathrm{H}^{+}, \quad \mathrm{p} K_{\mathrm{f} 2},
$$

where $K_{\mathrm{f} 2}$ denotes the formation constant for the introduced com-

TABLE 3

Surface Characteristic Parameters of Illite Samples from Different Origins

\footnotetext{
${ }^{a} S$ is the specific surface area after acidimetric titration.

${ }^{b} D_{\mathrm{S}}$ denotes the surface site density calculated using the equation $D_{\mathrm{S}}=\left(H_{\mathrm{S}} \times N_{\mathrm{A}}\right) /\left(C_{\mathrm{S}} \times S \times 10^{18}\right)$, ( sites nm $\left.^{-2}\right)$, where $N_{\mathrm{A}}$ is the Avogadro constant $\left(6.022 \times 10^{23} \mathrm{~mol}^{-1}\right)$ and $C_{\mathrm{S}}$ represents the solid concentration (g/liter). Moreover, the ion exchangeable sites are excluded for the WT illite sample.

${ }^{c}$ The $\mathrm{p} K_{\mathrm{fl}}$ is $2.74 \pm 0.023$ (44) for all three sample suspensions.

${ }^{d}$ The $\mathrm{p} K_{\mathrm{f} 2}$ for the WC sample is $10.71 \pm 0.066, V_{\mathrm{Y}}=5.92$; the $\mathrm{p} K_{\mathrm{f} 2}$ for the LPS sample is $9.85 \pm 0.085, V_{\mathrm{Y}}=13.97$; the $\mathrm{p} K_{\mathrm{f} 2}$ for the WT sample is $10.13 \pm$ $0.051, V_{\mathrm{Y}}=5.02$, optimized by FITEQL based on the actual measurements of acidic supernatants.

${ }^{e}$ The fitting models do not take into account the influence from ion-exchange reaction occurring at permanently charged surface sites. $V_{\mathrm{Y}}$ is the overall variance of the fitting procedure; $\sigma$ denotes the standard deviation of the relevant equilibrium constants.
} 

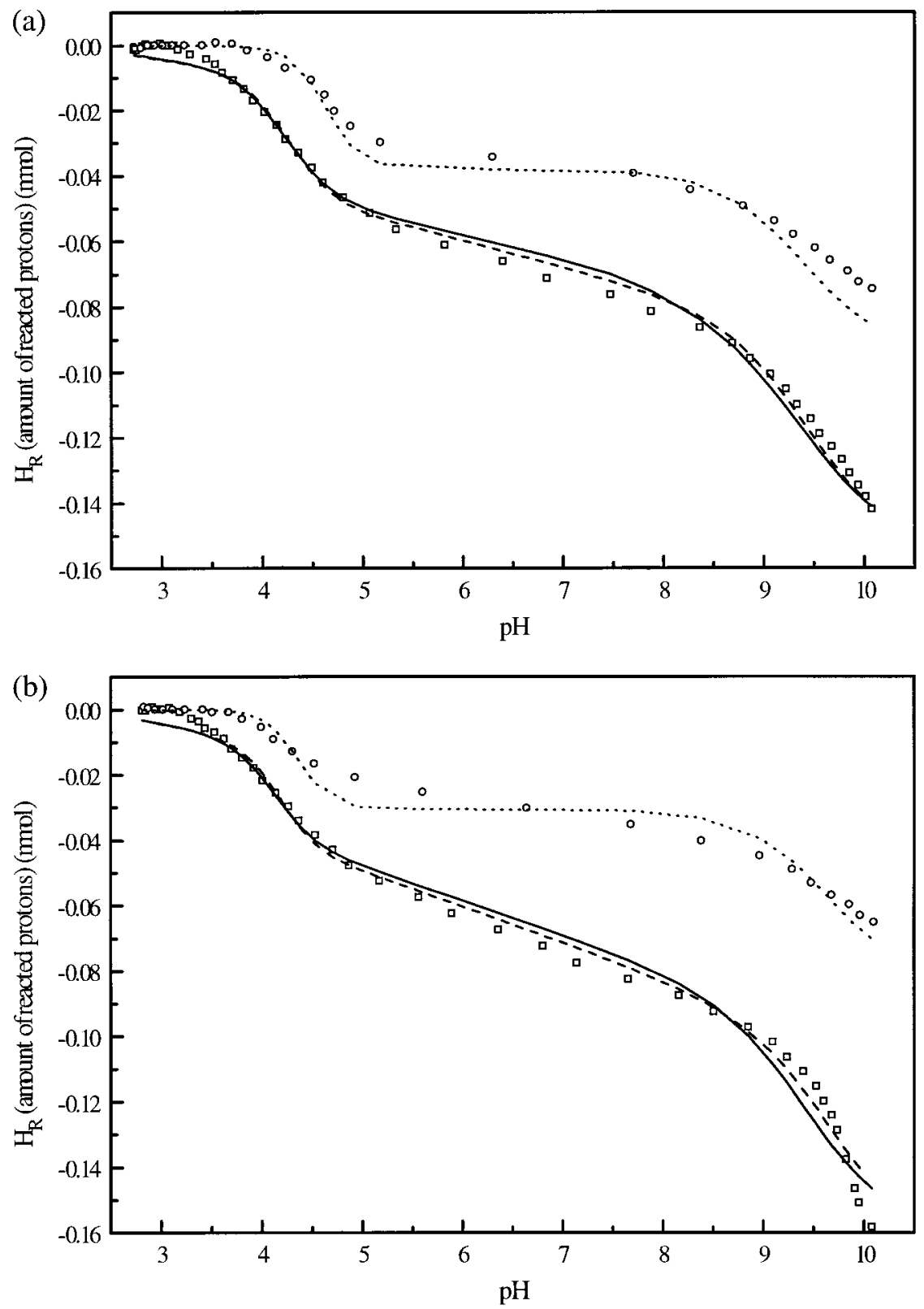

FIG. 5. Model illustrations of the potentiometric back titrations for different illite suspensions and the corresponding experimental data: (open circles) acidimetric supernatant, (open squares) $10 \mathrm{~g} /$ liter suspension in $0.1 \mathrm{M} \mathrm{NaNO}_{3}$, (dotted lines) simulation of the acidimetric supernatant using $\mathrm{Si}(\mathrm{OH})_{4}$ and $\mathrm{Al}^{3+}$ proton reactions, as well as complex formation between aluminum and silicic acids in aqueous solutions, (solid lines) description of the titration using Model I, (dashed lines) description of the titration using Model II, (a) WC illite, (b) LPS illite, (c) WT illite.

plex generated by the interactions between aqueous aluminum species and silicic acid during the alkalimetric back titration.

2. Illite suspensions. In this study, the surface acidity constants of aqueous illites from different origins were derived from the potentiometric titration data within the framework of the CCM due to the lack of other compelling evidence suggesting the need for a more complex model. Generally, a comprehensive description of interfacial reactions should include both ion-exchange and surface complexation (43). As for WC and LPS illites, since the use of background electrolyte $\left(0.1 \mathrm{M} \mathrm{NaNO}_{3}\right)$ effectively controlled the prevailing ionic strength, we only considered the acid-base behavior of the amphoteric surface hydroxyl group $\equiv \mathrm{SOH}$, and the weakly acidic surface functional group, $\equiv \mathrm{XH}$, accounting for ion exchange reactions, could be neglected. However, in the case of WT illite, the influence of the latter process should be considered, due to a more significant release of $\mathrm{K}^{+}$with respect to the other Chinese samples during the acidimetric titration (see Fig. 2). Based on comparison of the solubility data and titration curves, acidic dissolution, and subsequent complex- 


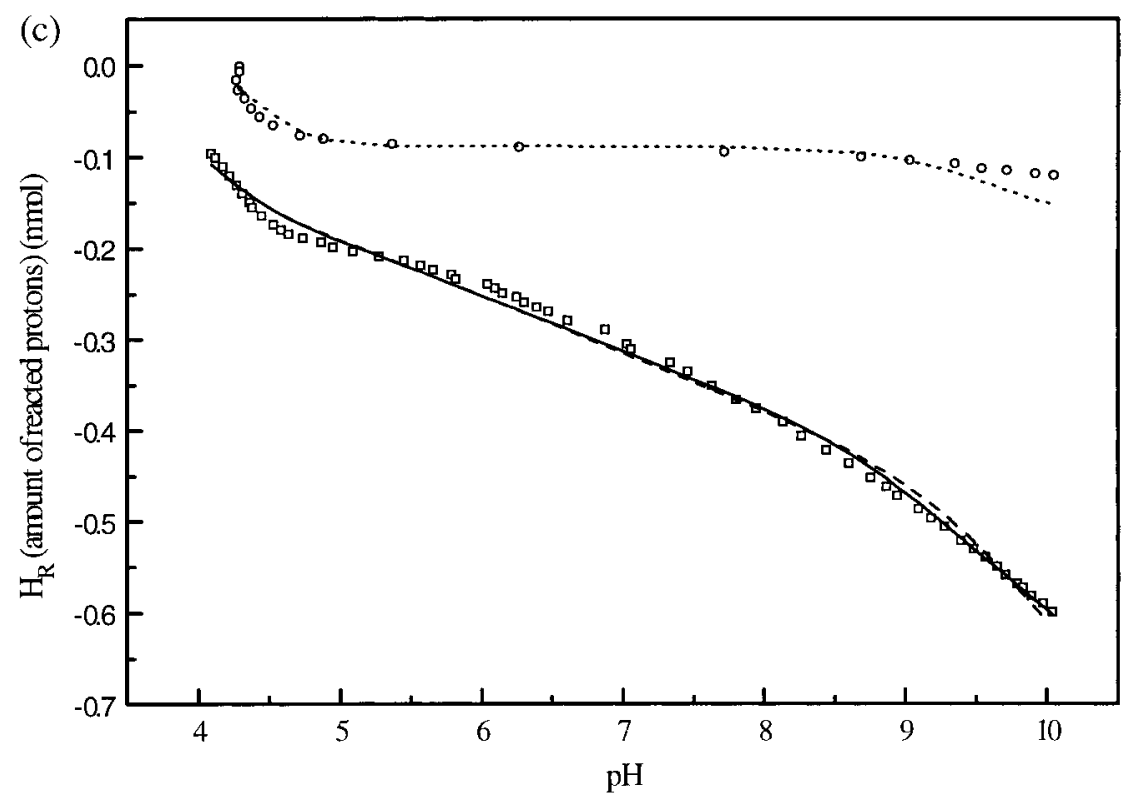

FIG. 5-Continued

ation or precipitation, may significantly affect the surface acidbase properties of aqueous illites. Moreover, a subsequent investigation using several spectroscopic techniques (45), such as IR spectroscopy, Raman scattering, and XRD profiles, provided some direct evidence for supporting formation of surface Al-Si complexes or precipitates, together with adsorption or binding of HAS species on the illite surface sites. Consequently, such chemical processes should be incorporated into model simulations.

In order to formulate these reactions, a set of parameters were imported into the stoichiometric matrix, including the acidity constants of $\mathrm{Al}^{3+}$ and $\mathrm{Si}(\mathrm{OH})_{4}$ in aqueous solution and the ICP-OES measurements of TOT(Si) and TOT(Al) in the acidimetric supernatant, as well as the relevant reactions of Al-Si complex formation, occurring in aqueous solution and at the illite surface sites. Then, two surface proton-reaction models were established to obtain the surface acidity constants, optimization being accomplished by tuning the corresponding parameters in the least-squares program FITEQL, including the electrical capacitance $(C)$, until the best fit was achieved. More details concerning surface properties and model description are given in Table 3 and illustrated by Fig. 5 .

(i) Model I

$$
\begin{aligned}
\mathrm{Al}^{3+}+\mathrm{H}_{4} \mathrm{SiO}_{4} \Leftrightarrow \mathrm{Al}\left(\mathrm{OSi}(\mathrm{OH})_{3}\right)^{2+}+\mathrm{H}^{+}, \quad \mathrm{p} K_{\mathrm{f} 1} \\
\equiv \mathrm{SOH} \Leftrightarrow \equiv \mathrm{SO}^{-}+\mathrm{H}^{+}, \quad \mathrm{p} K_{\mathrm{a}}^{\mathrm{int}} \\
\equiv \mathrm{SOH}+\mathrm{Al}^{3+}+\mathrm{H}_{4} \mathrm{SiO}_{4} \Leftrightarrow
\end{aligned}
$$$$
\equiv \mathrm{SOAl}\left(\mathrm{OSi}(\mathrm{OH})_{3}\right)^{+}+2 \mathrm{H}^{+}, \quad \mathrm{p} K_{\mathrm{SC}}
$$

Here $K_{\mathrm{a}}^{\text {int }}$ and $\mathrm{p} K_{\mathrm{SC}}$ represent the intrinsic acidity constant of surface reactions and the formation constant of the introduced surface complexation, respectively. In this model, the amphoteric hydroxyl groups, $\equiv \mathrm{SOH}$, on the illite surface were considered to be homogeneous and only subject to deprotonation to form the negatively charged surface site $\equiv \mathrm{SO}^{-}$. This assumption could be supported by the following evidence: first, the information in the Gran plot (Fig. 4b) implied that no obvious surface reaction occurred before $V_{\mathrm{eb} 1}$; second, the amount of reacted surface protons in each titration point $\left(H_{\mathrm{R}}\right)$ in Fig. 5 showed that only deprotonation occurred for all three illite samples, within the entire $\mathrm{pH}$ range $(\mathrm{pH} 3-10)$ studied. Furthermore, the positively charged surface species, such as $\equiv \mathrm{SOAl}\left(\mathrm{OSi}(\mathrm{OH})_{3}\right)^{+}$, could combine with the prevailing $\mathrm{NO}_{3}^{-}$ in illite suspensions, ascribable to the background electrolyte $\left(0.1 \mathrm{M} \mathrm{NaNO}_{3}\right)$ and addition of $\mathrm{HNO}_{3}$ during titration, to form the surface solid phase (45).

(ii) Model II

$$
\begin{aligned}
\mathrm{Al}^{3+}+\mathrm{H}_{4} \mathrm{SiO}_{4} \Leftrightarrow & \mathrm{Al}\left(\mathrm{OSi}(\mathrm{OH})_{3}\right)^{2+}+\mathrm{H}^{+}, \quad \mathrm{p} K_{\mathrm{f} 1} \\
\mathrm{Al}^{3+}+\mathrm{H}_{4} \mathrm{SiO}_{4}+2 \mathrm{H}_{2} \mathrm{O} \Leftrightarrow & \\
& \mathrm{Al}(\mathrm{OH})_{2}\left(\mathrm{OSi}(\mathrm{OH})_{3}\right)+3 \mathrm{H}^{+}, \quad \mathrm{p} K_{\mathrm{f} 2} \\
\equiv & \mathrm{SOH} \Leftrightarrow \equiv \mathrm{SO}^{-}+\mathrm{H}^{+}, \quad \mathrm{p} K_{\mathrm{a}}^{\mathrm{int}} \\
\equiv & \mathrm{SOH}+\mathrm{Al}^{3+}+\mathrm{H}_{4} \mathrm{SiO}_{4} \Leftrightarrow
\end{aligned}
$$

$$
\equiv \mathrm{SOAl}\left(\mathrm{OSi}(\mathrm{OH})_{3}\right)^{+}+2 \mathrm{H}^{+}, \quad \mathrm{p} K_{\mathrm{SC}}
$$


In the special case of WT illite, for which a large amount of $\mathrm{K}^{+}$was released relative to the other illites, when a high concentration of protons was consumed, cation exchange may occur at the weakly acidic surface sites $(\equiv \mathrm{XH})$. This hypothesis can be supported by the unusually high values of the capacitance needed to model the back titration curve for WT illite (see Table 3), implying that there is some acid-base reaction independent of the surface potential. Accordingly, the cation exchange reaction

$$
\equiv \mathrm{XH}+\mathrm{K}^{+} \Leftrightarrow \equiv \mathrm{XK}+\mathrm{H}^{+}, \quad \mathrm{p} K_{\mathrm{i}}
$$

was also considered, where $K_{\mathrm{i}}$ represents the reaction constant of ion-exchange, and the concentration of $\equiv \mathrm{XH}$ is assumed to be equal to that of $\mathrm{K}^{+}$released, namely, the concentration difference between the acidimetric supernatant and the neutral one (see Fig. 2).

The goodness-of-fit showed that the simple CCM, embodying a description of surface complexation or precipitation, was capable of portraying the essential surface acid-base characteristics of all three aqueous illites from different origins. All three illite samples yielded relatively stable numeric values for the formation constants of the proposed surface complexation or precipitation of HAS species, i.e., $\mathrm{p} K_{\mathrm{SC}}$ ranged from 3.063.53 in both models. After comparison, the $\mathrm{p} K_{\mathrm{a}}^{\mathrm{int}}$ values for the three illites are rather similar in Model I (3.76-4.09), showing some generalities in their acid-base characteristics; furthermore, the $\mathrm{p} K_{\mathrm{a}}^{\mathrm{int}}$ values in Model II (3.73-4.08) are very close to the corresponding ones in Model I, inferring that some correlation between the two models exists. Accordingly, Model I could be regarded as a simplification of Model II. Since both models suppose that deprotonation reactions dominate the surface behavior of the three illites, the influence of the silanol group, $\equiv \mathrm{SiOH}$, seems more significant than that of the aluminol group, $\equiv \mathrm{AlOH}$, which is not surprising considering the high percentage of $\mathrm{SiO}_{2}$ in the chemical compositions of these illite samples (see Table 1). Moreover, the fitting results of WC illite in our study are in accordance with those reported in the previous work (20). In the case of WT illite, the fitting efficiency of Model II, incorporing the ion-exchange reaction with $\mathrm{K}^{+}$, appears to be better than that without such a modification, as indicated by the $V_{\mathrm{Y}}$ values (see Table 3 ).

In this study, we consider that, after calibration using the equivalent points in Gran plots (20), the starting point of our titrations (ZPT) in an acidic range corresponds to uncharged surfaces, i.e., $\equiv \mathrm{SOH}$, and the illite surface species should be negatively charged, $\equiv \mathrm{SO}^{-}$, in the neutral $\mathrm{pH}$ region. Our choice of ZPT for aqueous natural illites is based on the actual analyses in Gran plots and negative values in the amount of protons consumed by surface sites $\left(H_{\mathrm{R}}\right)$ (see Figs. 3 and 5). Moreover, the zeta potential measurements in the other study of WC illite also confirmed this assumption (20).

In addition, the differences of the WT illite from the other illites probably originate from its large acid buffer capacity. It should also be noted that the effect of acidimetric titration on the specific external surface areas of all three illite samples was quite weak, particularly for WT illite (see Table 1). This implies that the basal planes inside the layer structure may contribute much more to the reactivity of illite in this study than might be suggested according to the typical crystal structure of natural illites. Perhaps other simulation models, e.g., the multisite complexation model (46), should be further considered to describe the specific surface properties of these illite samples. On the other hand, all the processes involved in the proton mass balance of WT illite should be evaluated, as otherwise, the general effect is to overestimate the proton consumption by the illite acid-base surface reactions, especially at low $\mathrm{pH}$. In other words, the concentration of surface sites $\left(H_{\mathrm{S}}\right)$, optimized by the FITEQL program, may represent an assembly of various surface sites, whereas the "real" $H_{\mathrm{S}}$ participating in the surface protonation and deprotonation may not be so significant. Similarly, this postulation is valid for the uncommon surface site density $\left(D_{\mathrm{S}}\right)$ of WT illite. As for the two Chinese illites, the same reactions appear to be negligible.

The surface speciation diagram of the WT illite sample including the ion exchange reaction $(\equiv \mathrm{XH} \rightarrow \equiv \mathrm{XK})$ is presented in Fig. 6. In acidic $\mathrm{pH}$, both types of surface sites are protonated, but in the neutral and alkaline $\mathrm{pH}$ range, they behave differently. One site is deprotonated and becomes negatively charged while the other exchanges $\mathrm{H}^{+}$for $\mathrm{K}^{+}$ions.

\section{CONCLUSIONS}

In this comparative study, we investigated the surface acidbase characteristics of three types of aqueous illites by potentiometric titrations. On the basis of experimental data and corresponding analyses, we draw the following conclusions:

(1) Proton reactions in the acidimetric supernatant of illite suspensions can be successfully described by those of $\mathrm{Al}^{3+}$ and $\mathrm{Si}(\mathrm{OH})_{4}$ in aqueous solution, together with the complex formation of hydroxyaluminosilicate (HAS) species. Since a significant release of illite structural elements occurs during the potentiometric titration, it is more reasonable to regard the acidimetric supernatant as the system blank when evaluating the surface site concentration $\left(H_{\mathrm{S}}\right)$.

(2) Two kinds of surface proton-reaction models, both assuming that surface complexation or precipitation of HAS species occurred on homogeneous surface sites, are proposed to capture the surface acid-base behavior of three illite samples from different origins. The special case of a strong acid buffer capacity and a large amount of $\mathrm{K}^{+}$released during acidimetric titration can be modeled by incorporating an additional assumption of ion exchange reactions at permanently charged surface sites into the model simulation. Within the scope of the CCM and considering the surface complexation and precipitation, both models can provide satisfactory de- 


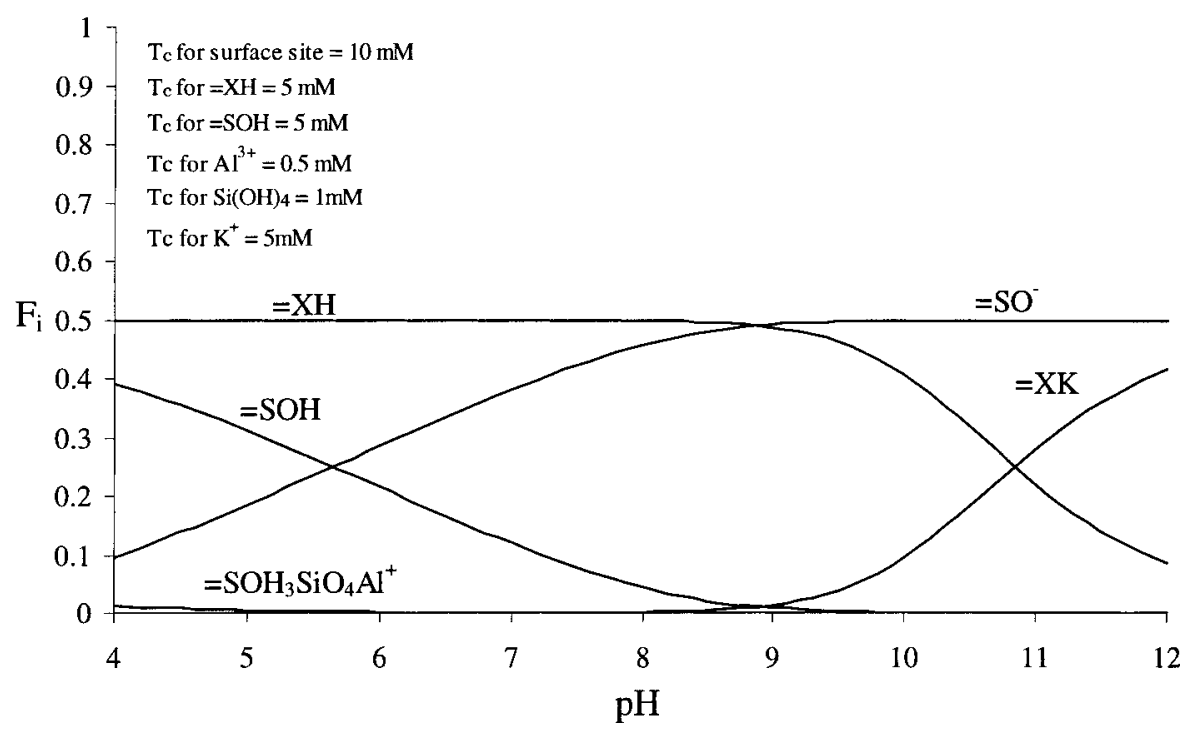

FIG. 6. Surface speciation diagram of WT illite sample as a function of $\mathrm{pH}$ established according to Model II. Surface reactions together with solution chemical reactions in Table 2 are included in the computer calculation.

scriptions of the experimental data recorded for all three natural illites.

(3) Some generalities are exhibited in the surface acid-base properties due to similar values of $\mathrm{p} K_{\mathrm{a}}^{\text {int }}$ for the three illites. The advantage of Model II is to further consider the influence of the interactions between dissolved aluminum species and silicic acid occurring in the system blank, i.e., the acidimetric supernatant. To some extent, Model I can be regarded as a simplification of Model II, since there are some similarities between the corresponding intrinsic constants. In addition, the formation constant for the surface (hydroxy) aluminosilicate complexes or precipitates exhibits relatively stable values for the three illite samples.

\section{ACK NOWLE D GMENTS}

We greatly appreciate Prof. Kaihui Chen of the Institute of Geology, Academy Sinica, and Dr. Ray Frost of Queensland University of Technology, Australia, for providing illite samples. We are grateful to Dr. Lars Gunneriusson and Dr. Liuming Wu, both of the Division of Inorganic Chemistry, Luleå University of Technology (LTU), for their assistance with SEM and specific surface area measurements, respectively. We also express thanks to Ms. Vania Engström and Mrs. Maine Ranheimer, Department of Chemical and Metallurgical Engineering, LTU, for XRD and carbonate measurements. And we acknowledge Dr. Douglas Baxter for his valuable editing suggestions. Finally, Mr. Liu is grateful to LTU for supplying funds to support the project.

\section{REFERENCES}

1. Chorover, J., and Sposito, G., Geochim. Cosmochim. Acta 59, 3109 (1995)

2. Wang, F. Y., Chen, J. S., and Forsling, W., Environ. Sci. Technol. 31, 448 (1996).

3. Wen, X. H., Du, Q., and Tang, H. X., Environ. Sci. Technol. 32, 870 (1998).

4. Lu, W. P., and Smith, E. H., Geochim. Cosmochim. Acta 60, 3363 (1996).
5. Manning, B. A., and Goldberg, S., Environ. Sci. Technol. 31, 2005 (1997).

6. Angove, M. J., Johnson, B. B., and Wells, J. D., J. Colloid Interface Sci. 204, 93 (1998).

7. Tessier, A., Fortin, T., Belzile, N., DeVitre, R. R., and Leppard, G. G., Geochim. Cosmochim. Acta 60, 387 (1996).

8. Bradbury, M. H., and Baeyens, B., J. Contamin. Hydrol. 27, 223 (1997).

9. Katz, L. E., and Hayes, K. F., J. Colloid Interface Sci. 170, 477 (1995).

10. Lützenkirchen, J., J. Colloid Interface Sci. 204, 119 (1998).

11. Charmas, R., Piasecki, W., and Rudzinski, W., Langmuir 11, 3199 (1995).

12. Török, S. B., Làbàr, J., Schmeling, M., and Van Grieken, R. E., Anal. Chem. 70, 495 (1998).

13. Turner, N. H., and Schreifels, J. A., Anal. Chem. 70, 229 (1998).

14. Bottomley, L. A., Anal. Chem. 70, 425 (1998).

15. Beene, G. M., Bryant, R., and Williams, D. J. A., J. Colloid Interface Sci. 147, 358 (1991).

16. Kubicki, J. D., Itoh, M. J., Schroeter, L. M., and Apitz, S. E., Environ. Sci. Technol. 31, 1151 (1997).

17. Du, Q., Sun, Z. X., Forsling, W., and Tang, H. X., J. Colloid Interface Sci. 187, 232 (1997).

18. Goldberg, S., and Glaubig, R. A., Soil Sci. Soc. Am. J. 50, 1442 (1986).

19. Motta, M. M., and Miranda, C. F., Soil Sci. Soc. Am. J. 53, 380 (1989).

20. Du, Q., Sun, Z. X., Forsling, W., and Tang, H. X., J. Colloid Interface Sci. 187, 221 (1997).

21. Browne, B. A., and Driscoll, C. T., Nature 256, 1667 (1992).

22. Exley, C., and Birchall, J. D., Polyhedron 12, 1007 (1993).

23. Xu, S. H., and Harsh, J. B., Soil Sci. Soc. Am. J. 57, 1271 (1993).

24. Farmer, V. C., and Lumsdon, D. G., Geochim. Cosmochim. Acta 58, 3331 (1994).

25. Exley, C., and Birchall, J. D. Geochim. Cosmochim. Acta 59, 1017 (1995).

26. Farmer, V. C., Fraser, A. R., and Tait, J. M., Geochim. Cosmochim. Acta 43, 1417 (1979).

27. Farmer, V. C., Soil Sci. Nutr. 28, 571 (1982).

28. Fitzgerald, J. J., Murali, C., Nebo, C. O., and Fuerstenau, M. C., J. Colloid Interface Sci. 151, 298 (1992).

29. Wada, S. I., and Wada, K., J. Soil Sci. 31, 457 (1980).

30. Farmer, V. C., Fraser, A. R., and Tait, J. M., Geochim. Cosmochim. Acta 43, 1417 (1979).

31. Exley, C., and Birchall, J. D., Polyhedron 11, 1901 (1992). 
32. Stone, W. E. E., El Shafei, G. M. S., Sanz, J., and Selim, S. A., J. Phys. Chem. 97, 10127 (1993).

33. Bouallou, M., Vielvoye, L., El Shafei, G. M. S., and Stone, W. E. E., Langmuir 14, 1072 (1998).

34. Ginstrup, O., Chem. Instrum. 4, 141 (1973).

35. Baeyens, B., and Bradbury, M. H., J. Contamin. Hydrol. 27, 199 (1997).

36. Ludwig, C., and Schindler, P. W., J. Colloid Interface Sci. 169, 284 (1995).

37. Zysset, M., and Schindler, P. W., Geochim. Cosmochim. Acta 60, 921 (1996).

38. Wanner, H., Albinsson, Y., Karnland, O., Wieland, E., Wersin, P., and Charlet, L., Radiochim. Acta 66/67, 157 (1994).

39. Duquette, M., and Hendershot, W., Soil Sci. Am. J. 57, 1222 (1993).
40. Westall, J. C., "FITEQL: A Program for the Determination of Chemical Equilibrium Constants from Experimental Data," Rep. 82-01. Dept. of Chem., Oregon State University, Corvallis, OR, 1982.

41. Smith, R. M., and Martell, A. E., "Critical Stability Constants. Volume 4: Inorganic Complexes.” Plenum, New York, 1976.

42. Pokrovski, G. S., Schott, J., Harrichoury, J. C., and Sergeyev, A. S., Geochim. Cosmochim. Acta 60, 2495 (1996).

43. Stadler, M., and Schindler, P. W., Clays Clay Miner. 41, 288 (1993).

44. Sjöberg, S., personal communication.

45. Liu, W. X., Sun, Z. X., Forsling, W., and Tang, H. X., submitted.

46. Hiemstra, T., Van Riemsdijk, W. H., and Bolt, G. H., J. Colloid Interface Sci. 133, 91 (1989). 